\title{
14. NURTURING SOLIDARITY IN DIVERSITY
}

\author{
The Superdiverse Shop Floor of Tower Automotive in Ghent
}

It is no coincidence that a focus on solidarity is returning to the center of public discussions in many Western European countries. International migration and neoliberal economic restructuring have created a situation of socio-political turmoil dissimilar from the historical conditions under which the modern concept of solidarity emerged. In January 2013 we started a research project called 'Diversity and Community Building' as we wanted to scrutinize the conditions in which innovative forms of solidarity become possible. It is a research project that is carried out by an inter-disciplinary research team of 15 scholars in cooperation with an advisory committee consisting of more than 60 frontline, intermediary and policy level organizations which are active in four settings of everyday life: labor, education, leisure and social housing, most of them situated in the Flemish region of Belgium and some of them in the city of Brussels. The underlying assumption of this project is that solidarity needs to be rethought and reformulated in a spatio-temporal framework that looks beyond the territorial nation state to solidarity practices hic et nunc. As educationalists we try to understand how social workers, community organizers, teachers, volunteers, delegates of trade unions and other engaged citizens create solidarity among people who do not have much in common apart from the school, the park, the factory, the sports field or the neighborhood center they share. We want to understand the modes of community interaction and the process of education that emerge through particular interventions of professionals in these places. For this chapter we go into one case in particular, the superdiverse shop floor of Tower Automotive in Ghent.

\section{SOLIDARITY AS A KEY ISSUE}

Over the last decade, many people have moved from place to place over the globe. These large migratory movements present challenges for people living within Western society today (Oosterlynck et al., 2015). The intensification of global flows of people creates increasing social and cultural diversity, resulting in a level and kind of complexity - called 'super-diversity' - surpassing anything previously experienced in society (Vertovec, 2007). Researchers refer to the day-to-day reality of our society as a "minority-majority" society. Differences between different groups are growing, and minorities have become majority (Vertovec, 2007). This 
increase of a multiplicity of diverse, and often antagonistic, ways of living lead to questions about what it actually means to be part of a collective with whom people feel attached to and with whom people are willing to share and redistribute material and immaterial resources (Stjernø, 2004). In this chapter we start from the following assumption: solidarity in super-diverse situations is possible and is already been practiced in schools and parks, in workplaces, sports fields, social housing projects and in neighborhood centers.

This focus on how people collectively engage in the here and now is different from the approach to 'solidarity in diversity' argued for by Putnam (2007). Responding to his empirical findings on how in the short and medium-term ethnic and cultural diversity has negatively impacted on solidarity, Putnam (2007) recommends a longterm strategy aimed at the construction of new and more encompassing national identities, "a novel 'one' out of a diverse "many"' (p. 165). We do not necessarily want to contest this claim, but what we would like to argue for is a much more in-depth understanding of the educational possibilities that emerge from everyday practices of people engaging with the multiplicity of cultures in a superdiverse society.

Although both "social cohesion and social solidarity are generally used interchangeably" (Vasta, 2010, p. 507) it is crucial for our analysis to make a distinction between the two concepts. Both concepts refer to the question of living together in an increasingly diverse society and culture but work from different perspectives on how diversity should be approached. The preferred term in current policy discourse is indeed 'social cohesion' and by definition it stresses the importance of integrating people into a collective with a homogeneous identity (Vasta, 2010). Community building efforts often share this focus and as Kearns and Forrest (2000, p. 996) argue the kernel of these practices is the idea "that a cohesive society 'hangs together'; all the component parts somehow fit in and contribute to society's collective project and well-being; and conflict between societal goals and groups, and disruptive behaviours, are largely absent or minimal". Such an approach is problematic as it "potentially privileges some residents over others - namely those with legal status and/or those who assimilate within the unified communal 'whole' over those without legal status and/or who represent 'difference' that might disrupt the unified communal 'whole"' (Squire, 2011, p. 294). Focusing on groups of people who do not 'fit' and who bear the burden to integrate into this communal whole also tends to reaffirm an essentialist frame of identity and culture. As Todd (2011) shows there is a particular ontology underpinning this approach which "turns a person into an aggregate of her cultural attributes: she bears these attributes like a mantle into encounters with others as though they stand for who she is" (Todd, 2011, p. 103). When educationalists try to intervene and facilitate a process of education based on this 'social cohesion' approach, they often focus upon the knowledge and skills migrants have to acquire in order to participate as full members of the communal whole, primarily understood in terms of what a neo-liberal labor market expects of people. It is an intervention that is based on strong but also conflicting beliefs in the abilities of a person: everyone can be a competitive entrepreneur but some people 
have to be qualified to do so through the acquisition of the 'proper' knowledge, insights, skills, and attitudes (Biesta, 2011). In any case, neither the standards, nor the imagined society that undergirds these educational initiatives are being widely challenged (Mollenhauer, 1986).

In shifting our focus onto solidarity we want to explore how a pedagogy which acknowledges vulnerability, weakness and fragility (Prieto, 2015, p. 306) encourages people to share and redistribute material and immaterial resources. More in particular, we are interested in what we want to call 'transformative modes of solidarity' that do not aim at dissolving differences between people into one clear-cut defined collective. As already indicated we want to locate these transformative modes of solidarity in a spatio-temporal setting that is different from the way these issues are managed by and through the nation-state. We shift to what diverse populations do and collectively engage in the here and now through everyday activities. From a spatial perspective, we move from the bounded territory of the nation state to the everyday places and practices in which people engage with the social and cultural differences they encounter. From a temporal perspective, a similar move is made from the imagined continuity through history of a national community to concrete places as schools, social housing projects, workplaces, neighborhood centers etc., where people jointly engage with the culturally and socially diverse groups of people that are present in these places. As educationalists, we believe we need to make this shift, away from a focus on education as a process of becoming a member of a predefined community to a process of being able to live in the concern for a 'we' for which a common denominator is not available and which always entails moments of transformation and disruption of the established order (Biesta, 2006). The emerging collective opens then the possibility of what Todd calls "an ontology of plurality' where the givenness of plurality (in all its contingency) can emerge and 'the boundaries of a democratic plurality" can be redrawn (Todd, 2011, p. 101).

\section{A SUPERDIVERSE SHOP FLOOR}

In this chapter we delve into a particular case, the superdiverse shop floor of Tower Automotive in Ghent (Belgium) and want to understand the significance of particular learning processes that can support transformative modes of solidarity. Tower Automotive is a worldwide producer of metal components for cars. We did our case-study in a division that is located in Ghent where Tower Automotive is a supplier for Volvo. Tower Automotive Ghent has 38 nationalities amongst the 350 employees (44 white collar, 265 blue collar and a fluctuating group of around $10 \%$ of the workforce who are on fixed-term contracts). There is a lot of diversity within the existing diversity and this diversity is not limited to cultural or ethnic backgrounds. Workers from African backgrounds for example, do not share the same status or the same origins. Some workers moved to Belgium because of marriage or family reunification, while other workers are former refugees. Some workers have support from networks of friends and family, other workers do not have these networks or 
support at all. A significant group of workers experience a range of problems with legal documents, are financially indebted and struggle to survive on low wages.

For this case-study one of the authors of this chapter made use of diverse research techniques. He conducted semi-structured interviews with key figures from the socialist trade union 'ABVV Metaal' and the Catholic trade union 'ACV Metaal (METEA)', the diversity officer of both trade unions and the sector delegates of both trade unions. He also interviewed the Human Resource Manager (HRM) who is responsible for the daily management of the factory floor. Apart from these interviews he worked for four weeks on the shop floor. He was concerned that there would be too much distance between the researcher and the workers in the factory and this would make conversations and in-depth interviews difficult. As one of the union delegates stated "once people see you as an outsider, they talk amongst each other about you, instead of with you". Every two hours he took a break to sit down and write his observations made at the assembly line. Conversations during longer breaks could be written down right away and at the end of each working day, he wrote more extensive fieldnotes reflections on them in the form of a diary. Lastly, he participated in some training and education initiatives that both trade unions organized for their members about anti-racism and intercultural competences on the shop floor and analyzed a set of documents relevant for the policy on diversity on the shop floor within Tower Automotive Ghent. All data was brought into NVIVO and in analyzing our data it became clear how the delegates of the two trade unions in this company are challenged by a differentiation of concerns on culture, religious rituals, multi-lingualism and a mosaic of issues connected to differences in economic and political positioning.

\section{DOING THINGS TOGETHER}

In the central hall of Tower Automotive Ghent images of all the workers are hung up and underneath these photos is the main slogan of this company: "Tower promotes diversity by giving equal opportunities to all." For this company, with its headquarters in America, dealing with the super diverse shop floor is about putting forward multiculturalism as a valuable and unifying standard for the company as a whole. Also, HRM and trade unions try to establish a whole range of actions that aim to 'deal' with diversity. For example, a nondiscrimination rule was introduced in this company following an incident of a racist slogan appearing in the toilets of Tower Automotive Ghent. The company decided to intervene and asked everyone to sign an agreement that discrimination and racism are not tolerated within factory walls. Trade unions as well as HRM also organize training sessions on antiracism and intercultural competences. In these courses they try to acknowledge the many differences among the workers and make these differences both understandable and workable for the employees of this company.

What research on diversity on the workplace (Estlund, 2006) shows, is that people can be encouraged to get along with each other, despite the relatively high degree 
of demographic diversity. Additionally, what is rather unique about the workplace is "its capacity to convene individuals who would not otherwise choose to interact and compel them to cooperate" (Estlund, 2006, p. 88). The process of working together depends on, and helps to produce, constructive and even amicable intergroup relations (Estlund, 2006, p. 81). As our analysis also shows, the outcome of working together on the shop floor is the normalization of difference or the acceptance of difference as an everyday and even banal feature of working life. An employee of Tower Automotive Ghent for example indicates that he appreciates his fellow workers "for what they do". He elaborates on this by saying:

Of course, we all judge each other. Maybe you think black man and think drugs or so. Or we think white man and see an authoritarian person. But what's different here is that we are forced to work together. One has to talk to another person. In a few years, and with time, the prejudices disappear when other things take over. If I now look at some people or think about them, it's through what they do. What they do and who they are starts to mix.

The observation of changed attitudes towards fellow workers made in this quote confirms what supporters of the 'contact hypothesis' over and over again have sought to demonstrate, that prejudices between groups are reduced when interpersonal contact under appropriate conditions becomes possible (Allport, 1958). What our research on Tower Automotive Ghent shows, is that a particular type of contact, a contact which encourages people to do things together, is likely to result in a changed attitude towards each other or at least temper tensions and prejudices and making feelings of respect, empathy and affinity possible. In line with Bauman (1995, p. 49) we understand this as a shift from simply occupying a shared space without interacting in any significant way ('being aside') to interacting with others as occupants of particular roles and expectation ('being with others').

People are joined together during an activity and shared objectives, tasks and roles substitute the possible tensions and prejudices towards each other. The underlying educational process is a cooperative form of learning as people learn to collaborate with others, learn to share objectives and apply problem solving strategies together. Sharing and redistributing material and immaterial resources become possible but only when it is suitable for the ongoing cooperation. The solidarity that becomes possible through collaborating on the arrangement of holidays in Tower Automotive is a good example of this. Holidays of two weeks are unfeasible for workers from Ghana, Jamaica, Russia or Ivory Coast as they want to visit their family in their countries of origin. Throughout this holiday period, a complex holiday roster was developed which manages to combine this particular demand for long leave by a group of workers with the right for every worker to take enough holidays. Another example is the request to pray during Ramadan and do less physically hard work during this period. Based on the data we were able to collect we could observe how the company but also delegates of trade unions tend to smooth down possible tensions and discussions that could arise from these particular issues. The solidarity 
that emerges, aims at integrating workers into a collective of participants that share a stake in performing a particular activity and is based on the importance of dialogue, learning to deal with conflicts and seeking to compromise.

But our analysis also shows that there are particular issues that challenge the clear-cut identification with Tower Automotive as one fixed collective and open up the potential for more transformative forms of solidarity. The first issue prompting this demand is the socio-economical vulnerability of some of the workers. Notwithstanding the fact that everyone on the shop floor has a formal job there are huge differences among workers in terms of job status and wage levels. Likewise, a significant number of workers with migrant roots are living in precarious living conditions. They do not have a social network they can rely on, they have limited possibilities as they survive on low wages and are not accustomed to the bureaucratic procedures that are required to obtain social security insurance, civil status etc. Delegates within both trade unions realize that the typical union actions of striking are not appropriate to respond to these extreme situations of social exclusion. They seek the proximity of the shop floor and are open for talks and support outside the walls of the factory floor. In doing so, they find themselves in a 'zone of discomfort' (Kunneman, 2007) as they recognize that they cannot build on existing institutional measures and proven methodological expertise. The vulnerable situation of the other cuts deep into what they were taught to as a professional. In search for a response they experience this zone of discomfort as worth exploring as it triggers the opportunity to loosen existing standards and positions in society. The issue of extreme vulnerability brings forward a situation of uncertainty, or even what could be called a crisis of judgement. Questions such as 'What should I do?' and 'On what grounds?' implicitly or explicitly urge them to reflect upon their own positioning. These questions are profoundly educational, not only for the professionals but also for the people they are working with. They provoke a site "of critique, of change, of newness" and more specifically an experience of a possibility "that the community we are taking ourselves to be representatives of can be changed, reoriented, broadened etc." (Ramaekers, 2010, p. 62).

In Tower Automotive the use of language is a second issue that is encouraging a potentially transformative form of solidarity. The language policy of Flanders, as one of the three language regions in Belgium, stipulates Dutch as the standard language to be used in all written and oral communication inside companies and organizations located within the Flemish territory. It is a directive that trade unions are much in favor of as it creates transparency about the communication that should be understandable for all the workers. But in the case of Tower Automotive both the company and the trade unions have chosen not to force workers to speak the Dutch language but only to encourage them to do so. Hence, in the day-to-day communication on the shop floor, the choice is made to talk the language that 'works'. Moreover, both in formal and informal communications multilingualism or experiments with using more than one language is the mainstream practice. What these experiments with multilingualism enhance, apart or beside its particular aim 
of getting the work done, is a more lightly or a less rule-governed way of working together. Multilingualism as an answer to the obligation of speaking one particular language, in particular the Dutch language, is then less disruptive or uncomfortable than the vulnerability of workers but it does enhance a space for sharing the capacity of communication, thereby untying one particular language as decisive in the way workers should define themselves as a collective. It reinforces a being together that exceeds a dynamic of rejections and identity claims. As an intervention it is about inviting people to co-create an activity where rules are still important but are less rigorous. The importance of this mode of interaction is also emphasized in research on conviviality, understood as relations where cultural, linguistic and religious particularities of people are present but not as fixed categories nor as sources of intractable problems (Nowicka \& Vertovec, 2014).

\section{WHAT IS EDUCATIONAL IN SOLIDARITY BUILDING?}

For many contemporary policy-makers, access to formal and informal solidarity is conditional on the integration of newcomers in the existing socio-spatial structures and the presumed cultural homogeneity of nation states (Kymlicka, 2015). This kind of 'affirmative' solidarity may become a politically conservative endeavor, however, if the order and hierarchies in which (new) groups are integrated are excluding and cannot be questioned. For this reason, we have argued in this chapter that there is need to track and trace transformative forms of solidarity in the everyday places where people work, live, play or study together. What we found on the superdiverse shop floor of Tower Automotive in Ghent is that working together on the shop floor does not only address people as occupants of particular roles and expectation but has the potential to enhance interactions that are disturbing some of the symbolic categories and the powerful structures that organize social life. Workers, HRM managers, trade union professionals etc. are asked to respond to particular issues while a common ground on which one can build this response, is shifting, fragile or not existing.

In the context of solidarity in diversity, the question is then whether solidarity is framed through an integrationist or transformative perspective. The former sees assimilation (i.e., becoming more similar to mainstream society) as a precondition for solidarity, whereas in the latter the confrontation with 'otherness' and the subsequent transformation of the socio-cultural and economical order to include other voices and subjects as equals is the very substance of solidarity in diversity. The former requires 'socialization', the latter implies 'subjectification' (Biesta, 2009). Socialization is about getting to know one's place, function and voice in a social order through learning processes that are implied in becoming part of a group. Learning understood as socialization inserts "individuals into existing ways of doing and being" (Biesta, 2009). Subjectification on the other hand refers to an educational experience of becoming a subject. It is not about the insertion of newcomers into existing orders, but about ways of being that hint at questioning and changing such orders. 
What we found on the superdiverse shop floor of Tower Automotive in Ghent were, what we want to call, minor acts or interventions which blur or even refute the way migrants fall between clear-cut social, cultural and legalistic conventions and categories (Squire \& Darling, 2013). The minor acts we observed, are not about the confirmation of one's own socio-cultural identity or the expression of specific sociocultural values of a certain group. They make the emergence of acting and speaking subjects possible who through their acts and voices transform and dispute pre-given identities. What these minor acts actually do is rather small, creating for example playfulness, experiments with multilingual conversations, being open for talks and support outside the walls of the factory floor. But these minor acts are at the same time very powerful as they enhance a sensibility that the terms on which people can respond collectively to the inevitable differences between people are not given. These minor acts install moments in which solidarity is practiced in a double sense: sharing and redistributing material and immaterial resources with 'newcomers' and also taking up the responsibility to renew this world in which we want to live, work and play together. From this perspective of minor acts, the focus of professionals (trade unions delegates in this case but also adult educators and community workers in a lot of other cases) is no longer on the conditions that people must meet, but on the kind of interactions that becomes possible. It is about enhancing interactions that are characterized by openness or indefiniteness to the ways others want to be and participate in the world we are living in. The emerging collective - or 'the coming community' in Agamben's terms (1999) lays no claim to identity and refuses any essentialist criteria of belonging. The starting point is then neither certainty nor clear knowledge on how professionals should help participants develop a specific set of knowledge, skills and attitudes. The question what it means to be part of a community becomes a radically open question and can only be addressed by engaging in particular relationships and practices rather than already defining the answers before the practice has even started (Biesta, 2006).

\section{ACKNOWLEDGEMENTS}

This chapter presents the results of one of the thirty case-studies of the interdisciplinary DieGem project on solidarity in diversity in Flanders. We would like to thank the Institute for the Promotion of Innovation through Science and Technology in Flanders (IWT-Vlaanderen) for their financial support.

\section{REFERENCES}

Agamben, G. (1999). Potentialities: Collected essays in philosophy. Stanford, CA: Stanford University Press.

Allport, G. (1954). The nature of prejudice. Cambridge, MA: Addison-Wesley.

Bauman, Z. (1995). Life in fragments: Essays in postmodern morality. Oxford: Basil Blackwell.

Biesta, G. (2006). Beyond learning. Democratic education for a human future. London: Paradigm Publishers. 
Biesta, G. (2009, March 4). Good education: What it is and why we need it. Inaugural Lecture for the Stirling Institute of Education. Retrieved from https:/www-gertbiesta-com.jimdosite.com/

Biesta, G. (2011, February 17). Learning in public places: Civic learning for the 21st century. Inaugural Lecture on the Occasion of the Award of the International Francqui Professorship, Ghent. Retrieved from https://www-gertbiesta-com.jimdosite.com/

Estlund, C. (2003). Working together: How workplace bonds strengthen a diverse democracy. Oxford: Oxford University Press.

Kearns, A., \& Forrest, R. (2000). Social cohesion and multilevel urban governance. Urban Studies, 37(5-6), 995-1017.

Kunneman, H. (2007). Sociaal werk als laboratorium voor normatieve professionalisering. Ethische Perspectieven, 17(2), 92-107.

Kymlicka, W. (2015). Solidarity in diverse societies: Beyond neoliberal multiculturalismand welfare chauvinism. Comparative Migration Studies, 3(1), 1-19.

Mayblin, L. (2016). Complexity reduction and policy consensus: Asylum seekers, the right to work, and the 'pull factor thesis in the UK context. The British Journal of Politics and International Relations. doi:10.1177/1369148116656986

Mollenhauer, K. (1986). Vergeten samenhang. Over cultuur en opvoeding. Amsterdam/Meppel: Boom.

Nowicka, M., \& Vertovec, S. (2013). Comparing convivialities: Dreams and realities of living-withdifference. European Journal of Cultural Studies. doi:10.1177/1367549413510414

Oosterlynck, S., Loopmans, M., Schuermans, N., Vandenabeele, J., \& Zemni, S. (2015). Putting flesh to the bone: Looking for solidarity in diversity, here and now. Ethnic and Racial Studies. doi:10.1080/ 01419870.2015 .1080380

Prieto, M. (2015). The other from an educational perspective: Beyond fear, dependence. Studies in Philosophy and Education, 34, 297-309.

Putnam, R. D. (2007). E Pluribus Unum: Diversity and community in the twenty-first century the 2006 Johan Skytte prize lecture. Scandinavian Political Studies, 30(2), 137-174.

Ramaekers, S. (2010). Multicultural education: Embeddedness, voice and change. Ethics and Education, $5(1), 55-66$.

Squire, V. (2011). From community cohesion to mobile solidarities: The city of sanctuary network and the strangers into citizens campaign. Political Studies, 59, 290-307.

Squire, V., \& Darling, J. (2013). The "minor" politics of rightful presence: Justice and relationality in city of sanctuary. International Political Sociology, 7(1), 59-74.

Stjernø, S. (2004), Solidarity in Europe. The history of an idea. Cambridge: Cambridge University Press.

Todd, S. (2011). Educating beyond cultural diversity: Redrawing the boundaries of a democratic plurality. Studies in Philosophy and Education, 30, 101-111.

Vasta, E. (2010). The controllability of difference: Social cohesion and the new politics of solidarity. Ethnicities, 10(4), 503-521.

Vertovec, S. (2007). New complexities of cohesion in Britain: Superdiversity, transnationalism and civilintegration. Oxford: University of Oxford: COMPAS.

Vertovec, S., \& Wessendorf, S. (Eds.). (2010). The multicultural backlash: European discourses, policies and practices. London \& New York, NY: Routledge.

Welch, R. V., \& Panelli, R. (2007). Questioning community as a collective antidote to fear: JeanLuc Nancy's 'singularity' and 'being singular plural'. Area, 39(3), 349-356. 